\title{
DON LOPE DE SIERRA CIENFUEGOS, FISCAL DEL CONSEJO DE CASTILLA EN EL REINADO DE CARLOS III
}

Lidia ANES

En la segunda mitad deI siglo XVIII, hubo personajes asturianos que destacaron como pensadores y como hombres de gobierno. Unos, como Jovellanos o Campomanes, son conocidos por todos. Sus escritos han llegado hasta nuestros días con plena vigencia, y aún hoy son objeto de estudio y debate. Otros no alcanzaron tanta notoriedad, a pesar de lo interesante de sus opiniones y de la importancia que tuvieron en la evolución de los acontecimientos históricos. Fs te es el caso de don Lope de Sierra y Cienfuegos. Don Lope fue catedrático de Salamanca, fiscal de la Audiencia de Valencia, fiscal del Consejo de Órdenes y fiscal del Consejo de Castilla, en donde coincidió con Campomanes. Ambos mantuvieron opiniones distintas en los dictámenes que sobre diversos asuntos les encargó el Consejo. Don Lope sostuvo una posición más conservadora y nèenos favorable a los cambios. Sus informes fiscales, a pesar de ser de gran interés, no alcanzaron la celebridad de los de Campomanes, y deben parte de su fama a las controversias surgidas entre ambos. Don Lope fue nombrado en 1766 consejero del Consejo de Castilla, aunque, por su edad, se le dispensó de acudir a las sesiones. Falleció en $1772^{\prime}$.

De esta manera se perdía, durante poco tiempo, dada su edad, un voto favorable a las reformas, pero se elininaba el obstáculo que habian supuesto los informes negativos de don Lope durante el tiempo en que fue fiscal. Concepción de CAsTro, Campomanes. Estado y reformismo ilustrado, Madrid, 1996, pág. 146. 
Quizá puedan parecer de interés menor los datos genealógicos de don Lope de Sierra, valorables sólo por los genealogistas. Pienso que no es así. Las relaciones familiares contribuyen a explicar el éxito de muchos personajes en los primeros años de su vida profesional. Así, Jovellanos recibió el apoyo «del tío sumiller» que no era otro que don José Femández de Miranda, hecho duque de Losada por Carlos III, primo de su madre y pariente, por la línea de los Cienfuegos, de don Lope de Sierra, que también tenía lazos de consanguinidad con Jovellanos, por el mismo linaje. Por ello, la información genealógica es de gran interés para estudiar apoyos e influencias, aunque no sea posible ver toda su importancia mientras no estén completas las distintas conexiones. También tienen interés para entrever fidelidades. recelos, admiraciones. Así, es seguro que el trato de don Lope de Sierra con don Pedro Rodríguez Campomanes no estuvo exento de las complejidades que habrían de derivar de su distinto extracto social. Aunque ambos eran del estado noble, uno - don Lope- pertenecía a familias de la cúspide de la jerarquía nobiliaria del Principado de Asturias. Campomanes era de familia hidalga, pero de las capas más bajas del estamento. kl hecho de que don Lope de Sierra hubiese sido colegial mayor y Camponanes manteista no habría de favorecer el buen entendimiento entre ambos.

No se ha hecho investigación alguna sobre don Lope de Sierra. Las noticias que sobre él han aparecido en publicaciones recientes se refieren sobre todo a sus divergencias con Campomanes, pero nada se sabe sobre su familia y oriunder asturiana. En las páginas que siguen trataré de mostrar los resultados de una investigación que he hecho sobre el personaje en sus aspectos biográficos y profesionales.

Don Lope de Sierra nació el 13 de noviembre de 1689. Fue bautizado en la iglesia parroquial de la Magdalena en la villa de Cangas de Tineo (hoy del Narcea) el 17 del mismo mes. Sus padrinos fueron don Baltasar Francisco Maldonado y Tinco y doña María Antonia de Valiés, sir abuela materna, condesa de Peñalba, vecinos ambos del concejo de Allande. Recibió los nombres de Lope Diego. Lra descendiente de dos familias asturianas de antigua nobleza, como atestiguan los padrones de la villa de Cangas de Tineo y de Pola de Allande, en los que están incluidos como pertenecientes al estado noble sus ascendientes paternos y maternos ${ }^{2}$. La nobleza de la familia fue probada varias

: A.I.N., Órdenes Militares, expediente 7.753; instrumento num. 6: Cores de nobleza del pretendiente, stu pathe, abuelos patemos y bisabueto como abueto materno y dos hetmatnos ente-

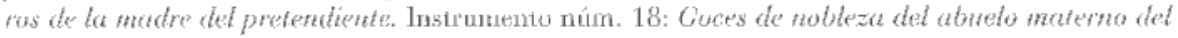
pretendiente y sizs häos hemanos enteris do la malre. 
veces al aspirar y obtener varios de sus miembros hábito de alguna de las órdenes militares ${ }^{3}$. El mismo don Lope solicitó, y obtuvo, en 1750, el hábito de Santiagot.

Por línea paterna, descendía de los señores de la casa de Sierra, cuyo solar estaba en el lugar de Llamas de Mouro, en el concejo de Ciangas de Tineo. En las averiguaciones que se hicieron en 1750 , se describe la casa de Sierra, de Llamas de Mouro, con su fachada principal, orientada a poniente, abierta con cinco ventanas rasgadas y balcones de hierro. En medio se abría una puerta grande, no muy alta, que servía de entrada. Encima de ella se podía ver un escudo de piedra en el que estaba esculpido un castillo al que un hombre, representado dentro de una barca, daba fucgo con un hacha encendida que llevaba en la mano. La construcción se completaba con tres torres; en dos de ellas, de bastante altura, se abría una ventana a oriente. La tercera, a modo de cubo» y más antigua, estaba coronada por almenas. En cuanto a los materiales de que estaba hecha la casa, los esquinales eran de sillería y el resto de mampostería de buena calidad.

La casa de Llamas de Mouro mantuvo lo esencial de su estructura hasta la actualidad. El detalle de la casa se acompaña con una descripción de la iglesia parroquial de Santa María de Brañas, de la que los Sierra cran patronos 5 . El re-

3 Don Diego y don Ituan de Sierra Osorio, padre y tío de don Lope, obuvieron en uiempos de Carlos II el hábito de Calatrava, seçún consta por Reales Cédulas de 13 de mayo de 1687. Sus expedientes pueden verse en A.H.N., Órdenes Militares, Calatrava; el de don Diego en el legajo 2.464 y el de don Juan en el 2.465. Sus tíus maternos, don Rodrigo y don José Franciscon rle Cienfuegos y Valdés, recilberon el hábito de Santiago por Reales Cédulas de 13 de mayo de 1699. Sus expedientes pueden verse también en el Archivo Histórico Nacional, Ordenes Militares, Santiago, legajo 1.967.

- Con este motivo se constituyó un experliente muy valioso por la información que de él se obtiene sobre los origenes y los antecedentes familiares de don Lope. A.II.N., Órdentes Militares, Santiago, exp. 7.753 .

El patronato de la iglesia de Nuestra Scñora de Brañas correspondía a los señores de la casa de Sierra. I Iabía sido fundada por don Diego re Sierra Osorio, bisabuelo de don Lope, quicn con su mujer, doña Antonia Valdés Flórez, la había dotado con diversos bienes de su propiedad. lin la escriura de fundación, fechada el 14 de noviembre de 1645, renuciaron a todo lo que pudiesen percibir por razón de su patronato, a «todo cuanto entrase por la puerta de la iglesia tanto en dinero de limosuas en los días de Nuesura Señora de Marzo, San Juan, San Antonio y otros santos, como a todas las ofertas que se hiciesen a la iglesia, respomsus y otros ingresos que correspondiesen al patronazgo, y que vendrían a rentar unos 150 reales. J Jos bienes con que dotaban a la iglesia no podrían ser vendidos ni enajenados. Los sucesivos curas sólo podrían urrendarlos o trabajarlos por sí mismos y disfrutar del usufructo. Tampoco las sucesivos poseedores de la rasa de Sierra podrían de ninguna manera reclamar o usurpar algúu bien de la kotación de la iglesia. A.H.N., Ordenes Militares, Santiagn, exp.7.753, instrumento núm. 21: Dotación por Diego Grurcía de Sierra y Doña Atttonia Ftórez Valdés stu mujer, bisabuetos patules rlet abucto paterno det pretendiente a favor de lat ighesia parroquial de Santa Marta de Brañas de este lugar de Llamas de Mouro. 
tablo unayor, dorado, tenía tres cuerpos. En el inferior se encontraba la custodia. Sobre ésta, una imagen de Nuestra Señora de Brañas. Rematándolo todo, la imagen del Santo Cristo. Tenía esta iglesia otros dos retablos: el de Nuestra Señora del Carmen, en el lado del evangelio y en el de la epístola, otro con la Sagrada Familia. Los dos retablos en los que estas imágenes se hallaban estaban dorados. Ambos eran de un único cuerpo. En el lado del evangelio, había un banco, y en el de la Epístola, una tarima".

Don Lope de Sierra descendía, por su madre, de los condes de Marcel de Peñalba y vizcondes de San Pedro Mártir de la Vega del Rey, señores del concejo de Allande y, con posterioridad, del coto de Caso?. El título de conde de Marcel de Peñalba fue concedido el 30 de mayo de 1649 a don García Valdés y Osorio. A su muerte le sucedió su hijo, del mismo nombre, que falleció sin descendencia. Como pariente más cercano e immediato sucesur en sus cásas y mayorazgos, el título pasó a don Rodrigo Cienfuegos y Valdés, en cuya línea seguía en tiempos de don Lope fortaleza en la villa de Pola de Allande. Fue deseria, en 1750, como ura catsa fuerte de un solo piso, cuya fachada principal estaba orientada hacia mediodía. Tenía en esta fáchada dos ventanas, una de ellas con una reja de hierro. En medio se abría una puerta de sillería de arco redondo sobre la que había un escudo de armas de piedra, labrado con cuatro cuarteles. En cada uno de los cuarteles se veían unas representaciones que simulaban ser llamas de fuego. El escudo estaba coronado por la Ciruz de los Ángeles, sobre la que había una flor. Estaba flanqueada esta fachada por dos torres, una de ellas de dos alturas, con tres ventanas que se sucedian verticalmente. La del piso inferior estaba protegida por una reja de hierro. A la otra torre estaba adosada otra fachada, también con tres ventamas. Había una tercera torre, más antigua, con tres ventanas. El palacio de Pola de Allande conserva, en la ac:tualidad, su trazado y planta según se describe a mediarlos del siglo XVIII. La capilla mayor de la iglesia parroquial de la Pola erá de patronato de los condes de Marcel de Peñalba. Había en ella um retablo dorado, con su custodia, sobre la que se encontraba una imagen dorada del Apóstol san Andrés. Sobre todo ello, un Cristo. El mobiliario de la capilla estaba formado por una silla de respaldo alto y en el lado contrario, un banco largo. Además de la ca-

A.H.N., Ordenes Militares, Suntiago, exp. 7.753 , núu. 20: Demaratión y reconocimien-

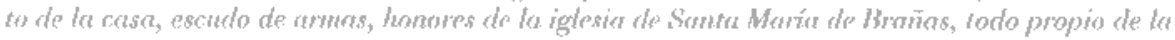
casa de Brotituts.

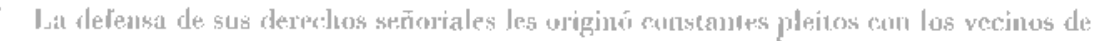

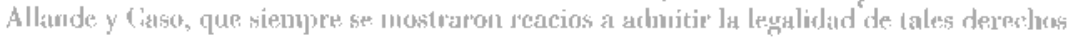

" A.H.N., (uonsejos, leg, 9.046, núm, 3. 
pilla mayor, había en la iglesia otra capilla, más pequeña, dedicada a Nuestra Señora del Rosario".

Don Lope era hijo de don Diego de Sierra Osorio y de doña Antonia María de Cienfuegos y Valdés. Contrajeron matrimonio el 26 de agosto de $1685 \mathrm{en}$ las casas del conde de Peñalba, padre de la novia, en Pola de Allande. En ese mismo día, fueron firmadas las capitulaciones nuatrimoniales. En ellas la madre del contrayente lo mejora con el tercio y quinto de todos los bienes libres que tuviese al tiempo de su muerte, con la condición de que quedasen vinculados perpetuamentc, igual que ella los había recibido a la muerte de sus padres. En este mismo documento, los condes de Marcel de Peñalba dotan a su hija con 6.000 ducados, a cuenta de sus legítimas paterna y matema. La entrega se habría de hacer en dos plazos: 4.000 en el día de la boda, kestando casados y velados" y los 2.000 restantes cuando el hijo primogénito de los condes heredase su casa y mayorazgos ${ }^{10}$.

Don Diego de Sierra Osorjo, caballero de la Orden de Calatrava desde 1687, padre de don Lope, era vecino y regidor del concejo de Cangas de Tineo, y señor de la casa de Sierra. Don Diego tabía nacido el 17 de febrero de 1651. Fue bautizado al día siguiente, apadrinándolo los señores de la casa de Pambley". Falleció el seis de agosto de 1738 , siendo enterrado, como mandó en su testamento, en la iglesia parroquial de Llamas, de lá que era patrono único ${ }^{22}$. Su mujer, doña Antonia María de Cienfuegos y Valdés, fue bautizada el 26 de junio de 1665 en la iglesia parroquial de la villa de Avilés. Sus padrinos fueron don Rodrigo de Valdés Alas, cura de Berdicio, y doña María Luisa de Valdés Alas ${ }^{13}$. Murió el 26 de junio de $1717^{1 t}$.

Don Diego y doña Antonia María tuvieron siete hijos: don Diego Alejandro de Sierra y Cienfuegos, quien, como primogénito, era el heredero del mayorazgo de Sierra. Fue colegial en el Colegio Mayor de la Santa Cruz de Valladolid,

"A.H.N., Ordenes Militares, Santiago, exp. 7.753, núm. 22: Demartación de la cotsa, escudo de armas, parroquia de la villa do ta Polu de Allande, propia del pretendiente por su línen materna.

tn A.H.N. Ódenes Militares, Santiago, exp. 7.753, núm.2: Escritura de rapitutarión de los padres del pretendiente don Diego do Sierra, Caballem del habito de Calatrava y doña Antomia Martu de Cienfuegos.

$"$ A.l1.N. Ordenes Miliare's, Santiagro, exp. 7.753, núm. 7: Fe de buntismo del abuelo patterno del pretendiente, fo de muerte de la martre, fe de muerte del padie, fo de bautismo del padre del pretendiente.

12 floidem.

1 A.II,N., Ordenes Militares, Santiago, exp. 7.753, núm. 10: Fe de bautismo de la madre det pretendiente.

it A.lI.N., Ortenes Militares, Santiago, ex]’. 7.753, núm. 7, cil. 
Juez Mayor de Vizcaya, Corregidor de la provincia de Guipúzcoa, miembro de los consejos de Hacienda y de Castilla y, desde 1726, Oidor en la Real Chancillería de Valladolid" ${ }^{15}$; don Lope, colegial en el Mayor de Salamanca del Arzobispo, y Fiscal, primero de la Real Audiencia de Valencia y después del Consejo de Castilla; don Bartolomé, clérigo presbítero; don José, dignidad de la Catedral de Oviedo; don Bernardino, don Lorenzo y doña María Antonia, casada con don José de Tíneo Osorio, vecino de Astorga y señor de Las Regueras y otras jurisdicciones en el Principado de Asturias ${ }^{16}$.

Los abuelos paternos de don Lope fueron don Diego de Sierra y doña María de Argüelles Miranda, señores de la casá de Sierra ${ }^{17}$. Don Diego, Regidor del conncjo de Cangas de Tineo, era liijo de don Diego García de Sierra, del lugar de Llamas de Mouro, poseedor del mayorazgo de Sierra y también regidor del concejo, y de doña Antonia Valdés Flórez, del lugar de Carballo, del inismo concejo de Cangas ${ }^{16}$. Doña María de Argüelles era hija de don Bartolomé de Argüelles, del lugar de Villar, en el concejo de Valdecarzana (hoy Teberga), y de doña Leonor Rodríguez de Miranda, de Taxa, en al mismo concejo ${ }^{\prime n}$. No tengo constancia de la fecha en que los abuelos paternos de don Lope contrajeron ma-

14. Como tal aparese inscrito en los pedromes del estarlo noble de la parrocuia de San Marvín y su amejo, Santa María de Brañas, a la que pertenecía el lugar de Llamas de Mouro, correspondientes a los uños 1731 y 1737 . A.H. N., Ordemes Militates, Santiago, exp. 7.759, mún . 6: Go-

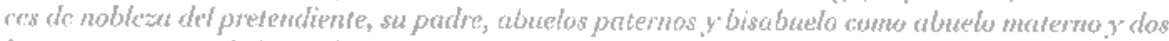

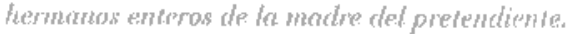

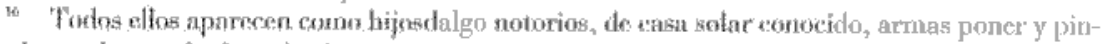

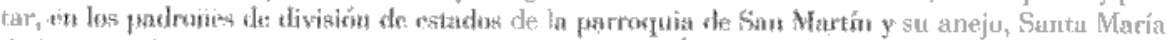

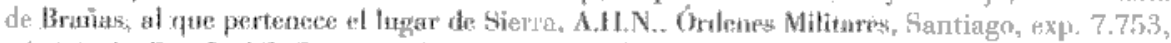

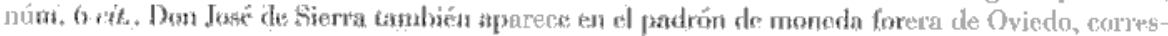

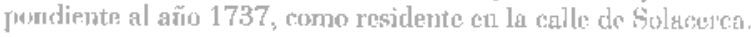

17. Don Disgo fue beutizado el 20 de dieientre de 1617 , y doña María, el 10 de rayo de

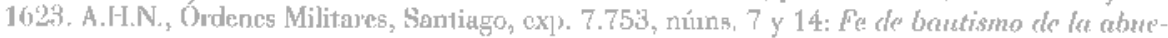
la perterma del pretendirnte.

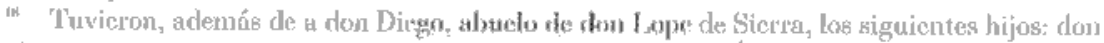

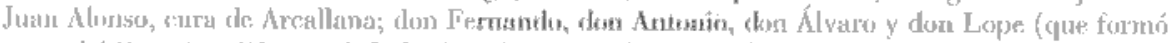

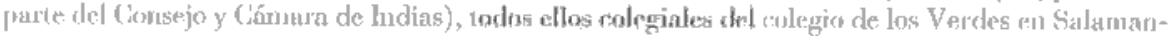

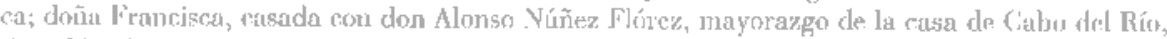
dojia Magdalena, cosada ton don Juan Bcrnardo de Tíneo, te. Zardaín, y doria Aldonza, munja del

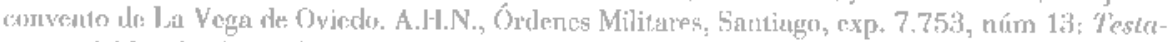
mento del bisabuelo, patre del abuelo putemo det pretendiente.

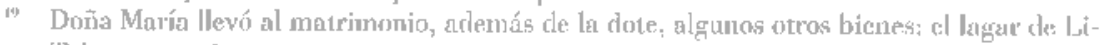
nares, en l'eberga, con las viñas y un prade pequeño siluado junto a él y otero prado en urı panje

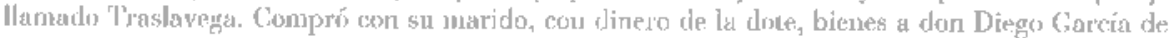

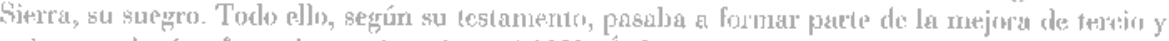

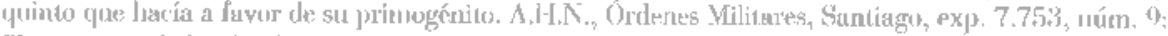
Teshamerno de la abuela paterna del pretendiente doña Mata de Argüelles. 
trimonio $^{20}$. Tuvieron dieciséis hijos, de los que alcanzaron la edad adulta quince. El primogénito fue don Diego, padre de don Lope. Le siguieron don Bartolomé, colegial del colegio de la Santa Cruz de Valladolid, en donde más tarde fue catedrático de Digesto. Se trasladó posteriormente a Italia, en donde fue Fiscal del Senado de Milán y Presidente de la Cámara Sumaria de Nápoles; don Bernardino Antonio, que fue cura de Lagunas de Somoza (León); don Juan, Caballero de Calatrava era, en 1694, Alcalde del crimen en Méjico. Murió al servicio del Rey en Manila, en donde fue Oidor; don Lope, colegial en el Colegio de la Santa Cruz de Valladolid y canónigo en Toledo; don Álvaro, cura de San Javier de Tuña; don Fernando, también colegial de la Santa Cruz de Valladolid y después Fiscal de S. M. en Lima; don Pedro, cursante en la Universidad de Valladolid. En cuanto a las hijas, doña Bernarda estuvo casada con don Nicolás Alonso, Regidor de la villa de Cangas; doña Francisca, con don Diego Flórez Valdés, de Tuña; doña Antonia, doña Leonor y una más cuyo nombre no se detalla, fueron monjas en el convento de la Encarnación de Cangas; doña María, casada con don Domingo Antonio del Busto y Montenegro, vecino de Tapia, y doña Magdalena, que casó con don Juan Queipo de Llano, vecino y Regidor del concejo de Tineo, natural del lugar de Santianes de Tuña ${ }^{21}$.

La casa de Sierra no se contaba, por la importancia de sus propiedades, entre las más ricas del Principado. Sus posesiones estaban situadas en cl lugar de su casa, en la aldea de Llamas de Mouro. Fueron aumentándolas los sucesivos poseedores del vínculo. El padre de don Lope, don Diego de Sierra Osorio, compró, con facultad Real, propiedades al marqués de Valdecarzana, situadas casi todas en el concejo de Allande ${ }^{22}$. También compró tierras a don Pedro Pertierra

2n Sí se incluye en la documentación una carta de pago en la que don Diego García de Sierra dice haber recibido de don Barlolomé Argüelles, su suegro, 3.502 reales a cuenta de la dote que éste había dado a su hija para contraer matrimonio. A.II.N., Ordenes Militares, Santiago, exp. 7.753, núm. 15: Carta de pago de la abuela paterna doña María de Argüelles a favor de don Bartolomé de Argïelles su padre. Dada por don Diego de Sierra Osorio, marido de dicha abuela.

21 A.T.N., Ódenes Militares, Santiago, exp. 7.753, núm. 9 cit.

* El marqués de Valdecarzana era uuo de los principales propietarios de Asturias. A mediados del siglo XVIII, era el mayor hacendado de los cotos de Quinzanas, Ranón, Soto de los Infantes y Muros; de las jurisdicciones de La Mata, San Pedto de Coalla y Valdecarzana y de los concejos de Santibáñez y Val de San Pedro. Archivo General de Simancas, Dirección General de Rentas: Libros del Mayor Hacendado. Principado de Asturias. T.ibros 445, 447 y 452. No obstante, los ingresos parece que no eran suficientes para hacer frente a todos los gastos que requería su vida en Mudrid y mantener el decoro propio do su condición. En 1736, don Sancho Fernández de Miranda y Ponce de Léńn, marqués de Valdecarzana, conde de Escalante, Villamor y Mayalde y vizconde del Infantado, tuvo que pedir facultad Real para imponer un censo solsre los bienes de su mayorazgo y poder, de esta forma, afrontar los gastos de la boda de su segundo hijo con una hija del conde de Peñaflor. A.II.N., Consejos, leg. 9.898, núm. 5. 
en el lugar de Albar. En su testamento, dejó mandádo que estos bienes formasen parte de la mejora de tercio y quinto, que habría de corresponder a su hijo primogénito, don Diego Alejandro, en caso de que cumpliese con todos los requisitos que se le exigían para heredar. Entre las propiedades de la casa de Llamas también estaban algunas extensiones de monte de corta, con hayas, robles y otros árboles silvestres, en el concejo de Allande ${ }^{2 * 3}$.

Por línea materna, don Lope era descendiente de los condes de Marcel de Peñalba. Sus abuelos matenus fueron don Rodrigo de Cienfuegos y Valdés, natural de la villa de Pola de Allande y doña María Antonia de Valdés y Alas, natural del lugar de Ferrero, en el concejo de Cozón. Don Rodrigo fue bautizado en la parroquia de San Audrés de Pola de Allandre ol 29 de agosto de $1637^{2+}$. Era conde de Marcel de Peñalba, vizconde de San Pedro Mártir de la Vega, Regidor de la ciudad de Oviedo, de la villa de Avilós y del concejo de Gozón. Aunque era venino de Avilés, sus Iugares de residencia habituales eran también sus casas de Luanco y de Pola de Allande" ${ }^{2 a}$. Don Rodigo era lijo do dor Balrasar de Cienfuegos, natural de P'ola de Mllande, y de doña María de Estrada, del lugar de Cebos, en Onís. Contrajo matrimonin el 31 de mayo de 1603 con doña María Antonia Valdés Alas; hautizada ol dos de febrero de $1644^{20}$. Doña María Antunia heredo de su padre, don Bernardo de Valdés Alas, la casa de Ferrero en Gozón, y de su madre, doña Toribia de Caso Cienfuegos, la casa de Caso en Piloña. Ambas rasas y mayorazgos los transmitió a su hijo mayor, don Rodrigo de Cienfuegos y Valdés al que, como primogénito, pasaron ludos los vínculos y mayorazgos, casas y oficios que poseían sus padres, siendo además mejorado en los testamentos de ambos con el tercio y quinto de sus bienes ${ }^{27}$. Don Rodrigo y doña María Antoniá uvieron como hijos a don Rodrigo, que llegó a ser capitán de caballería y caballero de la Orden de Santiago; don José Francisco, que también llegó a vestir el hábito de Santiago; doña María Antonia (madro de

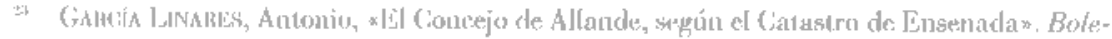

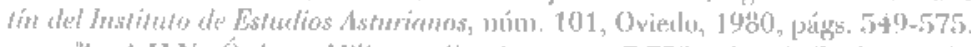

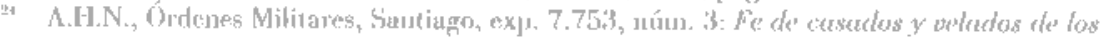
podres det protondiente. Fe do batusmo de su abuclo muteme.

2: lintre las elisposiciotes de su testamento se encuentra una velecente a su cnterramiento.

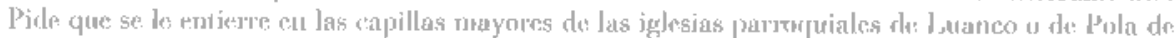

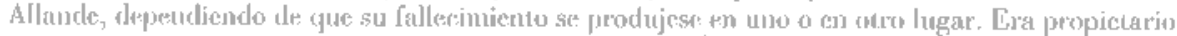

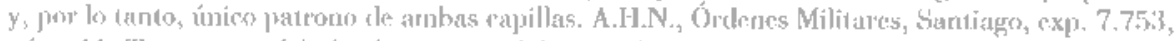

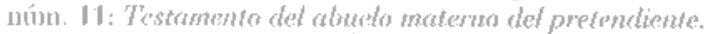

so A.J J.N., Consejos, Ordenes Militares, exp. 7.753, num. 12: Fe de bautistus de la cobrela

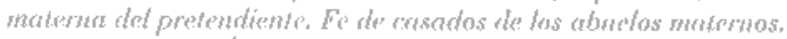

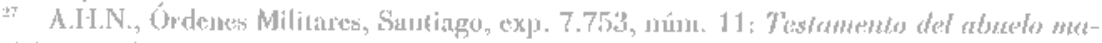
tono det pretombente. 
don Lope de Sierra), doña Francisca María y doña Josefa María. Ésta casó con don José Antonio de Faes, señor de la casa de Faes y Regidor de la ciudad de Oviedo. De este matrimonio nació una niña, doña Juana Margarita Josefa, que es citada entre los herederos legítimos de su abuelo, por haber fallecido ya su madre, aunque de la parte que le correspondiese habría de descontarse, como estaba estipulado en las capitulaciones matrimoniales, lo que había recibido como dote.

A pesar de ser titulares del señorío de Allande, los Marcel de Peñalba no figuran entre los mayores hacendados de ninguno de los departamentos en que el concejo fue dividido en el catastro que se hizo para establecer la Única Contribución. A mediados del siglo XVIII, los vecinos de Allande pagaban al conde, por razón de señorío, dos maravedís cada uno, si eran del estado llano y sólo uno si eran del estado noble. Además de tierras de labor, viñas y montes, tenía en el concejo el conde de Peñalba la propiedad de cuatro mazos para forjar hierro en los que se hacían calderas, sartenes, cucharas, herraduras y aperos de labranza. Estos mazos se conocían con los nombres de Arriba, de Abajo, de Colobredo y de La Puente. Obtenía de ellos anualmente la cantidad de 1.606 reales. EI titular del señorío era propictario también de dos batanes, uno sobre el río Fresnedo y otro en el término de Riobena. Le proporcionaban una renta de 115 reales. Tres molinos, en Fresnedo, le rentaban anualmente tres heminas de centeno. Como señor del concejo le correspondía al conde la designación del Merino Mayor y de los cuatro escribanos. Era también patrono de tres hospitales de albergue para peregrinos situados en el término ${ }^{2 a}$.

DON LOPE DE SILRRA,

FISCAL DEL CONSEJO DE CASTILLA

Don Lope de Sierra y don Pedro Rodríguez Campomanes sostuvieron opiniones contrarias en las ocasiones en que el Consejo de Castilla les encargó dictámenes ${ }^{29}$. Don Lope nació en 1689 y don Pedro lo hizo en 1723. Coincidieron como fiscales del Consejo de Castilla en la década de 1760. Entonces, uno sobrepasaría los 70 años y el otro apenas habría llegado a los 40 , por lo que sus informes no deben ser equiparados, ya que uno y otro fiscal no fueron hombres

2\% García LINAREs, *art. cit. \$

2" En 1763, informaron sobre los medios para hacer más eficaces las visitas de los escribanos y cvitar los abusos que se solían cometer. En 1764, lo hicieron sobre la admisión de jesuitas franceses; en informes de 1764 y 1765 trataron de los medios para erradicar la vagancia; en 1765 , los asuntos sobre to que se les encargó dictarninar fueron la abolición de la tasa de granos y la conveniencia de dictar una ley que pusiese fin a la amortización eclesiástica. Castro, Campomanes, págs. 132-137. 
de la misna generación. Don Lope estaba en el umbral de la ancianidad y don Pedro era una joven promesa del foro y de las letras, que ya había dado muestras de su talante progresista y favorable a los cambios. Las influencias ejercidas sobre uno y otro por lecturas extranjeras debieron ser muy distintas. Don Lope, por la fecha de su nacimiento, tuvo que sentir la influencia de los autores mercantilistas. Para él, es seguro que Uztáriz era una autoridad. Por ello, las precauciones que aconseja en sus informes fiscales son resultado del sentido común y de la experiencia. Teme las consecucncias de las aplicaciones repentinas de las reformas, sin baber sido precedidas de un estudio detaliado que demuestre wina verdadera necesidad de cambios, que en caso de ser imprescindibles, debian establecerse de una forma gradual. Don Lope es poco entusiasta con las innovaciones y escéptico con los efectos positivos que las medidas pudieran tener ${ }^{30}$. Campomanes, por el contrario, estaba al tanto y compartía las últimas corrientes de pensamiento. Defendió e intentó poner en práctica las ideas más avanzadas de la Ilustración, lo que le ocasionó la oposición de los sectores más conservadores de la sociedad española de la segunda mivad del siglo XVIII, includa en nuchas ocasiones la de los hombres encargados del gobierno del reino.

Los dictamenes sobre la conteniencia de esfablecer una ley de amortización

Acompanado de un escrito de Esquilache, fechado el 20 de junio de 1764 , fue remitido al Consejo, por orden de Su Majestad, una representación del Fiscal de Hacionda, don Franscisco Carrasco, en la que exponía, como útil y conveniente al reino, limitar las adquisiciones de bienes raíces por las manos muertas ${ }^{11}$. El Consejo debía estudiar el asunto, para lo que era preceptivo que informaser dos fiscales. Correspondió el dietanen a don Pedro Rodríguez de Campomanes y a don Lope de Sierra. Debía también ser oída la opinión de don Francisco Carrasco. Una vez vistos Ios dictámenes o alegaciones, los señores de gobierno habrían de proponer a Su Majestad lo que considerasen más conveniente ${ }^{\text {I2. }}$.

: En el informe sobre el libre comerciu de granos dirá tue *... la experiencia ha herho ver

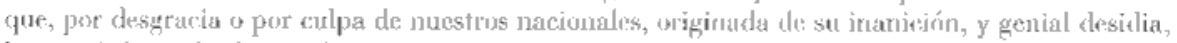
hace inutiles todos ios suidados que nuestros soberanos poner ers adelantar nuestras tonvenien-

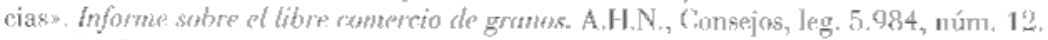

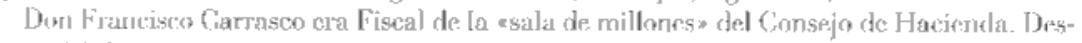
de 1761 , recibia honores, antigüedad y sucldo rle consejero de Castilla, aunque nunca fue nombrado cono tal Cinsprizo Campomanes, pág. 136.

32 Sobre los dietámenes y alegariones que se sucedieron resulta imprescindible cornsultar el estudio preliminar de Francisco Tomás y Vadiente a la edición facsinuilar del Tratado de la kega. lia de Amontizución, Madrid, 1975, púgs. 7-38. 
Después de estudiar detalladamente el asunto, teniendo en cuenta todos los antecedentes que sobre él había, la situación general del reino e, incluso, las soluciones que se habían propuesto en otros países, Campomanes y Carrasco coinciden en considerar imprescindible una nueva ley que prohibiese nuevas adquisiciones de bienes raíces por las manos muertas. Don Lope de Sierra es de parecer totalmente contrario. Lope de Sierra no presentó su dictamen hasta después de haberlo hecho los otros dos fiscales, por lo que tuvo la oportunidad de rebatir algunos de sus puntos en sus escritos ${ }^{39}$.

Campomanes y Carrasco coinciden en sus razonamientos sobre la conveniencia de promulgar una $l \mathrm{ey}^{34}$. Carrasco, para demostrar lo necesario que era su establecimiento, alude a las muchas peticiones que sobre este asunto se habían hecho desde antiguo. Hacía más de 240 años que los reinos, reunidos en Cortes, habían solicitado que se limitasen las enajenaciones de bienes en manos muertas $^{35}$. En el siglo XVII, el Consejo de Hacienda volvió a exponer a Su Majestad los daños que este asunto estaba causando al reino, proponiendo algunas medidas para remediarlo. Ninguna de estas quejas había sido oída y, desde entonces habían pasado muchos bienes raíces a manos muertas ${ }^{3 / 1}$. Carrasco y Campomanes consideran que cuántos más bienes tuviesen las manos muertas, más facilidad habrían de tener para adquirir, y mayor habría de ser el número de miembros del estamento eclesiástico, con los graves perjuicios que todo ello ocasionaba a los seculares, a la Corona e incluso al mismo clero?

33 Carrasco y Campomanes presentaron sus dictámenes el 26 de junio de 1765, y Lope de Sierra no lo hizo hasta el nueve de septiembre. Transcurtió más de una año desde el monento en que llegó el escrito de Esquilache al Consejo hasta que los fiscales presentaron sus alegaciones.

अ Garrasco reconoce en su alegación que ha contado con la ayuda y colaboración de Campomanes: "no se hubiera atrevido a dar el menor paso si el espíritu y franqueza del Fiscal don Pedro de Campomanes no le hubiera dilatado, presentándose a frecuentes conferencias y conliándole su dictamen», Colección de las Alegaciones Fiscales del Excmo. Señor Conde de Campomanes. Publícala con autorización de la Regencia del Reino don José Alonso, Fiscal y Magistrado que ha sido del Tribunal Supreno de Justicia, tomo III, Madrid, 1842, pág. 87.

as Se refiere a las peticiones hechas en las Cortes de 1523 en Valladolid; de 1525 en Toledo; de 1528 en Madrid; 1532 en Segovia; 1534 en Madrid; 1537 en Valladolid; 1552 en Madrid y las que se celebraron entre 1592 y 1598 también en Madrid.

Tho Según los informes de que disponíar los fiscales Campomanes y Carrasco, eran propiedad de los vasallos laicos 61.196.166 medidas de tierra. Las manos muertas poseían 12.204.053 medidas, que, según sus cálculos eran la sexta parte de las tierras de las 22 provincias de Castilla y León. A cada individuo de manos muertas (incluyendo a sus sirvientes), correspondían casi 87 medidas de tierra. En ningún otro país católico las propiedades de manos muertas habían llegado a tales extremos. Alegaciones, págs. 157-158.

37 Según Francisco Carrasco las manos muertas tenían más ventajas para comprar bienes que el resto de la población, ya que pagaban menos tributos, no solían pagar diezmos, podían labrar mejor y podían especular con sus frutos, reservándolos a la espera de que sus precios fuesen 
La corona habría de tener interés en limitar el proceso de concentración de bienes en manos muertas, porque ocasionaba grandes perjuicios al Real Erario, al dejar de cobrar el derecho de alcabala por las posibles sucesivas ventas que pudieran verificarse de los bienes que pasaban a manos de iglesias, comunidades o fundaciones, al quedar estancados para siempre en los nismos dueños ${ }^{* 3}$. También dejaba de cobrár la Real Hacienda ciertos tributos de los que estaba exenta la propiedad eclesiástica.

Dosde la emtrada en vigor del Concordato de 1737, los bierces de manos nuertas estaban sujetos a los mismos tributos que los de los legos. Quedaban exeptuados los bienes que se adquiriesen mediante primera fundación, por lo que, segúur Campomanes, si no se ponía freno a las fundaciones, era nulo el efecto de la concesión pontificia ${ }^{34}$. Por otra parte, las adquisiciones de manos muertas estaban exentas de todos los demás tributos "personales, mixtos, domativos y derramas públicas».

Resultaba también muy perjudicial para la Corona la pérdida de jurisdicción en los territorios que pasaban a manos muertas, lo que, a juicio de Campomanes, se convertía en una razón fundantentel farła que no se auturizase esta clase de enajenaciones sin la facultad Real. Veían con preocupación los fiscales Campomanes y Carrasco cómo en estos territorios aumentaba la confusión en el orden pulílico y civii, ya que los magistrados reales no podían en mu-

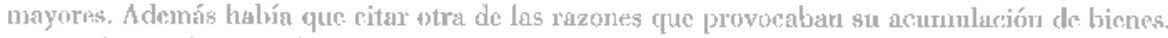
que era lo que Carraseo llema *la jicdad de la ración*, las don aciones de los particulares. Opinaba Campomanes que a medida gue ammentuha el nimero de celesiásticos, la población diseninuia y la fuerza del Estado se volvía aparente y caduca. Alegnciones.

JB Campermanes cree que no cube dudar de la facultad del soberano para impedir estas era-

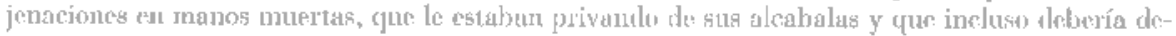
volver a manos libres todos aquellos bienes adquirides sin liceneig real por las manos muerias desjués de su fundación. En palabrus de Camponnanes, *imperfecta seria la constitución de una

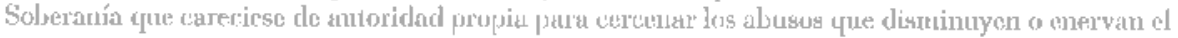
Erarion. Alegationes.

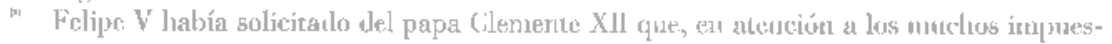

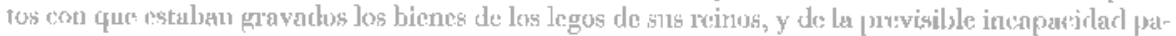

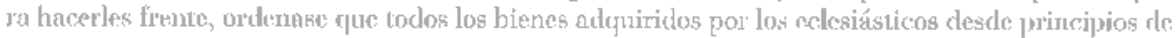

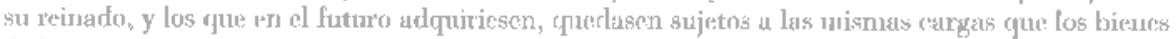
da lrgos. El papa accedió a esta petición pero sćlo para los tributos regios y prara los bienes que pásascu a manos muertas descle el día de la fíma del Cincordato, exceptuando los bienes de prinucra fundución. A cambio de csto, los bicies que se adquiriesen en el futuro habrían de quedar libres

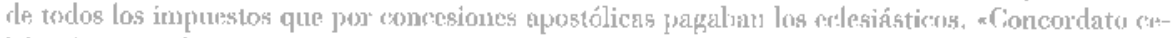
lehrado entre ed Rey de: España y ol Pontífico ('lemente XIh, ol cual se firmó en Roma a 20 de sep-

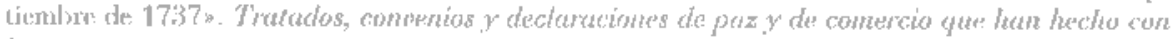

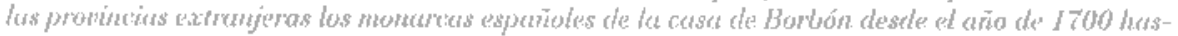
ta el dín. pur den Alcjandro del Cantillo, Madrid, 1843, págs. 291-303. 
chos casos ejercer la jurisdicción Real ordinaria. En este sentido, la Corona se había visto también perjudicarla por el Concordato de 1737, en el que el papa Clemente XIl impuso que no pudiesen los tribunales scglares obligar a las manos muertas a satisfacer los tributos que adeudasen, porque este asunto debía quedar exclusivamente en manos de los obispos ${ }^{40}$.

Según los fiscales, el aumento de la extensión de tierra en poder de manos muertas era muy perjudicial pará los propietarios laicos y para los contribuyentes en general. Argumentaban que había propictarios que se veían compelidos a vender sus propiedades por no poder hacer frente a los numerosos tribu10s, diezmos y cargas a cuyo pago estaban obligados. Los eclesiásticos, en cambio, al estar libres de nuchos de cllos, podían ofrecer hasta un tercio más del precio que estuviesen dispuestos a pagar otros interesados en la compra, por to que eran sienpre preferidos en las ventas. Por tanto, podía haber propietarios que, al vender sus tierras, se viesen convertidos en arrendatarios o jornaleros. Campomanes afirmaba que aumentaba en los pueblos ell número de jornaleros a medida que aumentaban las adquisiciones de manos muertas. El paso siguiente había de ser la despoblación y la miseria, ya que al carecer de bienes ráces e incluso de hogar, los vecinos abandonaban sus pueblos ante las primeras dificultades surgidas en su nueva condición ${ }^{+1}$. Este era un problema que debía ser teuido muy en cuenta, porque "ningún Estado será rico, cuyo pueblo sea pobre: ni podrá dejar de ser pobre el comín de los vasallos seculares si se los deja deshacerse desmedidamente de sus bienes raíces" ". Para atajar este mal, debía prohibirse a los particulares que por cualquier medio enajenasen sus bienes en manos muertas, lo que los obligaria a venderlos a particulares. Tales adquisiciones habrían de ser indiferentes al común de las gentes, ya que sólo supondrían un cambio de propietario, y los bienes estarían sujetos a los mismos tributos y obligaciones a que estaba sonetido el propietario anterior.

En opinión de los fiscales Campomanes y Ciarrasco, el mismo clero se veía

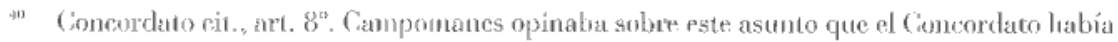
perjudicado y disuninudo la Juriscliceicon Real en las tieras que se iban emajerando, lo que hasta entonees no vecurín.

t1 Según Campomanes, estas personas * deben mirarse conno unds plantas parásitas, someras de las liemas fue al menor impulsu de: un mal año, no teriendo bienes raices que empeñar, malbaratan sus gamados o sus mucbles, y se echan sucesivantente a la mendignez. Alegaciones, pág. 116. Esta cra, para Camponanes, la causa del gran número de vagos que cubrían los caminos de España. Observalua también que en doride los veciuos tenían bientes ráces, propios o forales (pone como ejenplos Asturias, la Moniañ. Viscaya, Guipúzcoa, Navarra), sólo había mendigns en los pucblos grandes, y se tenía a cosa de menos valer dejar la labranza y echarse a liu orteras.

t2 Aleguriontes, pág. 118. 
perjudicado por el aumento de la propiedad amortizada, sobre todo el clero socular, ya que las manos muertas, por concordatos 0 por exenciones, no solían pagar diezmos. A este hecho habría que añadir que los particulares, cada vez más empobrecidos, no podrían contribuir al sostenimiento de las parroquias, lo que explicaría que muchas estuviesen arruinadas, sin poder atender a los fieles. Los religiosos mendicantes también se veían perjudicados, porque su manutención debía salir del también empobrecido pueblo.

Una vez expuestos los grandes males que ocasioraba la ilimitada enajenación de bienes ráces en manos muertas, consideraban los dos fiscales que era de extrema necesidad, "prescindiendo del arreglo que mira al pasadon, evitar que se agravase el daño con posteriores adquisiciones. Coincidían Campomanes y Carrasco en la opinión de que era imprescindible limitarlas mediante el astahlerimiento de una ley general en la que el rey habría de prohilir a los vasallos y clérigos seculares «cnajenar sus bienes raices y derechos incorporales por título oneroso o lucrativo en manos muertas * ${ }^{* 3}$. Además, recomendaban que quedase anulado cualquier contrato o disposición que se hubiese hecho en este sertido, devolviendo los bienes a los familiares. Lo mismo habría de hacerse con las herencias de los que entrasen en religión, para que, de ningún modo, pudiesen incorporar sus bienes a manos muertas. Campomancs y Carrasco consideran que, como todas las leyes generales, ésı habría de perjudicar a alguien, en este caso a algunos cclesiásticos y comunidades religiosas, pero el bien genteral de la sociedad exigía su establecimiento. Podría compensarse el perjuicio indirecto que causase a unos pocos con el bien general de la sociedad civil, y nunca se podría calificar como injusta una ley que pretendía lograr el equilibrio de los cuerpos del Estado ${ }^{4}$. Desde cualquicr punto que se mirase, se veía la necesidad de limitar estas adquisiciones. No dudaban sobre el procedimiento para hacerlo pero, según Carrasco, el problema residía en la potestad: żdónde estaban los límites de la inmunidad de la Iglesia? Y, ghasta dónde llegaba la antoridad del rey? Tampoco en este aspecto los fiscales tienen duda alguna. Isa durla, propia de tiempos pasados, debía quedar ya olvidada, porque la situación se había agravado y el rey tenía la obligación de poner freno a es-

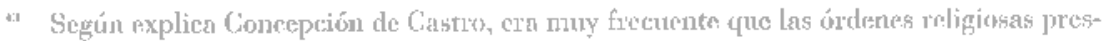
tasen dineso a ccnso a peyucños propietarios, pura quedarse con sus propiedades curando ésios no podías pagar (Campomornes, pág. 138)

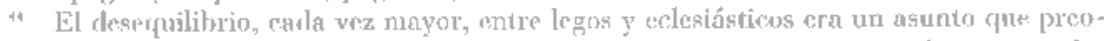
cupabia a los flos fiscules, como se puede intuir por la insistercia con que en sus alegaciotes uluflon a él. 
tos daños. Si no lo hiciese, «faltaría a sus cargos de padre de los pueblos y cabeza suprema del Fistado ${ }^{45}$.

Don Francisco Ciarrasco y don Pedro Rodríguez Campomanes elaboraron un borrador con los puntos que a su juicio debían estar incluidos en la ley general de amortización ${ }^{4}$. El fin de esta ley o pragmática habría de ser la prohibición a las manos muertas de adquirir, por cualquier medio, bienes raíces o derechos perpetuos sin haber obtenido antes la licencia Real ${ }^{47}$. Para que esta licencia pudiese concederse debería contar con los votos favorables de tres cuartas partes de los miembros del Consejo de Ciastilla y, en caso de que los bienes que se deseaba amortizar estuviesen en despoblado, sería necesario consultar con Ios pueblos existentes en un contorno de tres leguas. EI privilegio de amortización sería exclusivamente para unos bienes concretos, con una extensión y lindes ya conocidos, y no para adquirir por valor de una determinada cantidad, y no se concedería cn caso de haber perjuicio a terceros. Si los bienes a amortizar estaban destinados a aunentar la dotación de fundaciones de asistencia (hospitales, hospicios, dotes para casar cloncellas), sería suficiente con que el Consejo tuviese la certeza de que a estas fundaciones les convenía la adquisición de los nuevos bienes, despachándose los privilegios sin más averiguaciones ni consultas.

Los fiscales Carrasco y Camponanes presentan la ley por ellos propuesta

t5 Opinaba lirancisco (arrasen que el anparo, la defensa y la constante vigilancia que el Príneipe debía tener sobre sus súbrlitos, lo obligalsan a velar por sus inteceses sobre rodas las cosas, incluso sobre elo más sagrado», laciendo parar', si luese pereciso, eel curso de las bulas pontificias». Alegaciones, pág. 101.

th Son 14 puntos en los que se recoren los requisitos rque habrían de cumplir en el futuro las manos muertas para poder incorporar más propiedades. Alegaciones, págs. 138-142. Este paso le parece a don Lope precipitado, pues debería primeto dictaninar Su Majestad solme la convenienría o no de la prbblicación de la dey de amortización.

tT Se habrían de entender cono manos inutrtas a las iglesias, capillas, emitas, monasierios. conventos y colegios de regulares, sus hospicios, residencias y misiones; órdenes terceras, beneficios y capellanías colativas o laicales; cofradias, hermandades, montes de piedad, hospitales, casas de misericordia, de expósitos y de hospicio; colegios y semininarios eclesiásticos, píos o seculates y cualquier clase de obra pía. Por hienes raíces se entenderían las tierras, molinos, batanes, herrerías, casas, fál,ricas, edificios y *los artificios que estén fijos al suelon. Támbién se entendcrían así los censos perpetuos y los redimibles impuestos sobre bienes raíces de los particulares legos y de clérigos seculares. No serían comsiderados como bienes raíces los censos redimibles impuestos sobre bienes de otras manos muertas o sobre los propios y arbitrios de los pucblos ni efectos de villa juruis y cargos sobre la Real Haciemdu; rentas o pensiones sobre gremios o cualquier conpañía general de comercio público. Para todo lo no considerado como bienes raices tenían libertad de adquisición las manos muerias. También li tessdeían para mejorar sus terrenos y edificios y para edificar sobre sue to que ya fuese propis o que adquirieran posterirmente com el privilegio Real. Alegaciones. 
como noderada, pues no niegan el derecho de las manos muertas a la adquisición de biene's raíces. Lo que pretendian era que, en el futuro, estas adquisiciones no se hiriesen sin línite. Para ello era necesario que tuesen precedidas de estudios previos que demostrasen que eran necesarias para la mano nuerta que pretendía adquitir y que no perjudicaban a terceros. Si el rey velaba porque esto se cumplieses, no faltaría a su obligación de proteger a sus súbditos, seglares 0 laicos.

Gomo ya se ha visto, el Fiscal don Lope de Sierra presentri su alegación a iste proyecto de ley de amortización después de háber sido presentados los de Camponanes y Carrasco. Quizá a esto se deba la impresión de que su escrito tiene dos partes claramente diferenciadas: la primera, en la que apenas hace referencia al asunto del que debía tratar, limitándose a exponer otros intentos yarocidos del pasado, y una segunda parte, en la que hace una crítica de algunos de los punios contenidos en el borrador de la pragmática presentado por (ianpomanes y Ciarrasco.

La alegación de don Lope de Sierra se fundamenta en que la ley de amortización no es urgente ni nocesaria, y parece incluso que le rosulia molesto te-

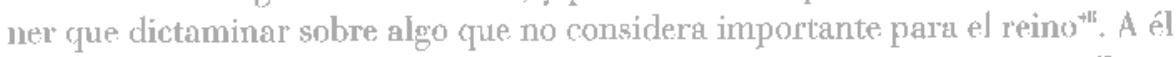
It Irarece más conveniente limitar el número de eclesiásticos, pero como Canupomanes y Carrasco «juzgan necesaria la ley de amortización fundando en ella la lelicidad del Reino", expone su dictamen sobre cste asurito". [Ino de sus argumentos más repetidos es que ya se había estudiado la posiluilidad de linuitar las amortizaciones durante el reinado de Carlos II, y entunces no se había considerado un problema importante. Desde entonces no se había vuelto a hablar de ello, y el Concordato de 1737 había remediado los perjuicios que ocasionaba al Estado la constante adquisición de bienes raícess por las manos muertas.

Veía don Lope con preocupación las consecuencias que esta ley, en caso de publicarse, habría de tener en las relaciones entre la Santa Sede y la Monarquía española. J a que para Campomanes y Carrasco era un aturutu qute no debía in-

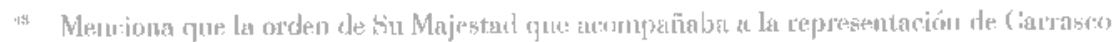

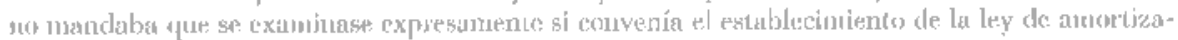

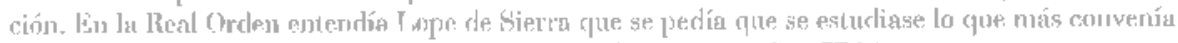
al Estado y al modo de lograrlo. A.H.N., Curkejos, leg. 5.984, nums. 77 bis.

1" Para ilustrar su opinión de que la ley de amodización no erá al renedio para bos males

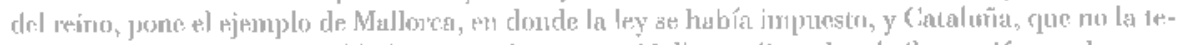

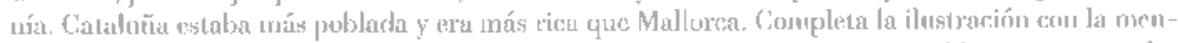

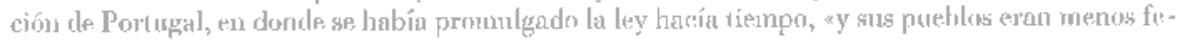
licas que las de este Reinos. 
terferir en los intereses del remo, se convertía para don Lope en una de las cuestiones más importantes que se debería tener en cuenta antes de tomar ninguna medida definitiva. Creía que, antes de la publicación de la ley, en el caso de que e] Consejo consultase a Su Majestad a favor de promulgarla, debería el soberano hacer presentes al papa los perjuicios que se experimentaban, a pesar de la providencia de 1737, para que «permita» la privación de la adquisición ilimitada de bienes raíces ${ }^{\text {ne }}$. El rey tendría que saber hacer compatible el beneficio del reino con el fuero de la immunidad ecesiástica, cuidando del perjuicio que podría causarse a quienes gozaban de este fuero.

Don lupe, tanto por formación como por experiencia, es sumamente respetuoso con las instituciones, por lo que presenta los aspectos negativos de la medida que se quería tomar.

Parte notable de la alegación de don Lope se dedica a adelantar algunas de las razones que las comunidades monásticas podrían oponer al establecimiento de esta ley. No consideraba que luesen tan ricas como se pensaba. La mayor parte de las comunidades eran tan pobres que no podían sostenerse ni mantener el culto con la decencia que sería de desear". En su opinión, desde el reinato de Carlos II el estado eclesiástico había adquirido muchos bienes, pero había perdido muchos más. Una de las causas de las pérdidas sufridas por las comunidades religiosas había sido la rebaja del interés de los censos del cinco al ires por ciento ${ }^{52}$. Como consccuencia de la Pragmática de 1705 habían resultado perjudicadas las comunidades eclesiásticas como censualistas y beneficiados los seculares censuatarios. Para don Lope, aunque por imposición legal, debían considerarse los réditos que los eclesiásticos habían dejado de percibir como «una enajenación hecha por las comunidades religiosas a favor do los vasallos seculares ${ }^{\text {n.3. }}$.

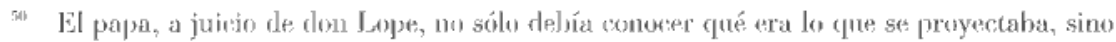
que debería también permitirlo. No debería el rey olvidarse del daño que esta ley podría causar: * sería opuesto a la justa y piarlusa intención de Su Majestad la persuasión de la conveniencia, con ofensas de la justicia y de la piedadr.

5 Distingue tres rlaseb de rommiclades religriusds, según su rigueza. La primera cstaba integrada por las que temían más de lo que necesitaban. I a segunda clase la formarían las que tenían lo mecesario. La teresa, que superaba por niumero de sus miembros a las otras dos juntas, estaba integrada por las comunidades pobres que sólo podían subsistir gracias a la piedad de los lieles. Habría que añadir orra clase, integrada por lodas aquellas commidarles a las que sus reglamentos prohibían adquirir bienes.

se Se refiere don Lone a la rebaja del año 1705. A.II.N., Consejos, lib. 1.475, núm. 21; Madricl, 12 de febrero de: 1705: Pragmática que Su Majestad manda publicar sobre la ninoración de los réditos de los rensos. Fn el año 1750, se dictó la misma pragnática para la Cocona de Aragón.

Adeunás, muchas conunidades religiosas, cargadas de censos en lavor de particulares, que por lo que parece no pagarn sus intereses, no podían enconirar comprador para sus propiedades. 
No era ésta la única quiebra econónica que las comunidades religiosas habían tenido en el siglo XVIII. La decadencia de los efectos de la villa de Madrid y la rebaja de los juros habían llevado al extremo de la necesidad a muchas obras pías y comunidades religiosas. De esta rebaja había salido beneficiado el Real Erario y, por lo tanto, los vasallos seculares. Todo ello llevaba a don Lope a opinar que las obras pías y conumidades religiosas, a las que ahora se quería perjudicar más con la ley de amortización, estaban nás pobres en el siglo XVIII de lo que lo habían estado en el XVII. Otra razón alegada por don Lope para demostrar la imutidiad de una ley de amortización lue la de que, al contrario de lo que se pensaba, no era tan dificil para las manos muertas vender sus bienes. Opinaba que los generales de cada orden solían conceder lacultad para vender siempre que fuese por un motivo justo y por verdadera necesidad. Tampoco en esta situación solía negar su autorización el Romano Pontífice. Por lo que había llegado a 51 conocimiento, incluso se daba el caso de comunidades que. querían vender sus bienes y no encontraban comprador laico.

I.á crílica al borrador de pragmática presentado por don Francisco Cadrrasco y don Pedro Rodríguez (iampomanes se hasa en la excesiva rigidez que se pretendía dar a la ley. Resultarían especialmente perjudicadas las comunidarles más pobres, pnes aunque podían apelar a la piedad del rey para que les concediese privilegio de amortización, los requisitos que tendrían que cumplir previamente harian casi imposible que pudiesen obtenerlo. Le parece a don Lope demasiado estricto el capítulo $8^{\circ}$ de la minuta o borradorit. Si para decidir sobre otros ásuntos «gravísimos» bastaban los votos de la mayor parte del Cónsejo, y los de dos terceras partes para proponer al rey una ley nucva o la derogación de alguna antigua, era excesivo a su juicio lequerir para este asunto los votos afirmativos dc las tres cuartas partes de los consejeros. Además, bastante cargulo de asuntos estaba ya el Conscjo, para ahora aumentar aun inás los temás sobre tos que debía decidir. Por otra parte, la necesidad de oír a los pueblos en los que pstuviesen situados los bienes que se quisiesen amortizar hacít muy difícil la consecución del privilegio: por la animadversión que solían tene. a esta clase de adquisiciones, La neresidad, segúm se contenía en el proyecto de Campomanes y Carrasco, de que en el moncento de solicitar la liccnciá Real tuviesen que estar perfectamente delimitados los bienes que se querian amortizar.

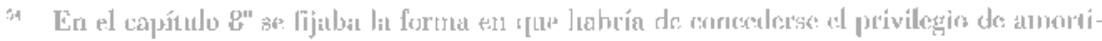

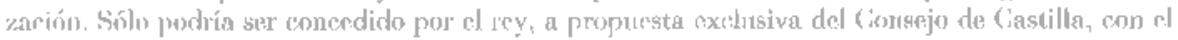
wotu favorable de lres rulartas parites de sus miembros, y después de haber sido oído el parecer del

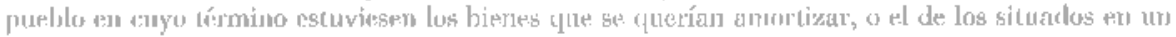
contorno de tres legnass en raso de que estuviesen en rembothado. También habría de virse el parecer del Procurador General rel Réno y del Fiscal del fionsejo. 
dificultaría aún más el acceso a la propiedad. La delimitación, por los requisitos que habrían de superarse, sería un trámite complicado y largo, y se corría el riesgo de que, una vez estudiado el caso, si se informaba afirmativamente y se concedía la licencia, el donante o vendedor hubiese cambiado de opinión. Todo se complicaba aún más cuando los bienes que se querían amortizar procedían de una cesión en testamento o cuando se quería invertir una cantidad determinada en dinero en bienes diversos, ya que en este caso sería necesaria una autorización para cada una de las adquisiciones.

Según don Lope de Sierra, la nueva ley conduciría, más que a limitar, a impedir definitivamente la adquisición de más bienes por las manos muertas. Todos los capítulos de la minuta estaban elaborados para impedirles el acceso a la propiedad. Por lo tanto, si finalmente el Consejo juzgaba necesaria la ley y Su Majestad autorizaba su publicación, por su obligación como rey debía proveer los medios necesarios para evitar la ruina en la que, a juicio de don Lope, caerían las comunidades religiosas, especialmente las nás pobres, que verían cerradas todas las posibilidades de adquirir bienes, por no poder afrontar los grandes gastos que supondrían los trámites necesarios para conseguir la Real Licencia.

A pesar de la representación enviada a Su Majestad por la Dirección Ceneral de Millones de los Reinos en defensa de los argumentos de los fiscales Carrasco y Rodríguez Campomanes, el Consejo, en votación celebrada el 18 de julio de 1766, decidió informar a Su Majestad de que no convenía el establecimiento de la nueva ley. Fue favorable a su establecimiento el voto del Presidente del Consejo, conde de Aranda y el de cinco consejeros: don Pedro Colón de Larrétegui, don Miguel de Nava, conde de Troncoso, don Pedro Ruiz y Egea y don Luis del Valle Salazar ${ }^{\text {nh }}$.

$* \dot{x} *$

Los planteamientos de don Lope de Sierra sobre la propiedad de manos muertas, comparados con los más radicales de Campomanes y de Carrasco, hacen ver al personaje en sus actitudes de hombre prudente, experimentado y conservador. Teme un enfrentamiento con el papa, si se va más lejos de lo debido en cuanto a limitar la capacidad de la Iglesia para adquirir bienes. Aparece como buen conocedor de la propiedad eclesiástica, a su juicio no tan importante ni tan descuidada como solían señalar los ilustrados más intrépidos que desea-

5i Alegaciones, pág. 181. 
ban cambios radicales. Don Lope, en su dictamen, se muestra cauto, conocedor de las consecuencias que pueden tener las medidas radicales cuando se aplican sin la conveniente cautela. Su dictamen sobre la abolición de la tasa de granos y la libertad de comercio de cereales en el interior del reino muestra análogas cualidades de prudencia. El estudio del personaje, de su formación y del papel político que desempeñó en la España de su tiempo permitirá comprender mejor las complejidades y las implicaciones del movimiento ilustrado, en el que tan importantes fueron las influencias generacionales. Cabe preguntarse si don Lope de Sierra fue consciente de que limitar las posibilidades de adquirir por la Iglesia era ir en contra del derecho de propiedad y de la libertad humana. Pensaba que la Corona tenía que proteger el Derecho de propiedad, tanto cuándo los titulares de él eran individuos como cuándo se trataba de instituciones. Limitar las posibilidades de adquirir era cercenar el derecho, y por consiguiente, cercenar la libertad. 